\title{
A Novel Approach for Apexification: A 2-year Follow-up
}

\author{
${ }^{1}$ Pradnya V Bansode, ${ }^{2}$ Sagar S Deshpande
}

\begin{abstract}
Aim: To present a novel approach for nonsurgical management of large periapical lesion with open apex by using White Portland Cement to create an apical plug leads to substantial periapical healing.
\end{abstract}

Summary: Radiographic examination in this case indicated previous root canal treated, immature tooth with a wide-open apex and a periapical radiolucency. After cleaning and shaping Triple antibiotic paste was placed for 3 weeks. Hydroxyapatite was mixed with sterile saline \& placed beyond the canal apex until with the aim of creating a periapical barrier. WPC powder was then mixed with sterile water, carried inside the canal to create apical plug $(4 \mathrm{~mm})$ and obturation. The remainder of the canal was filled with thermoplastic gutta-percha. This was followed by post \&core and PFM crown. Clinical follow-up of 2 years revealed absence of clinical symptoms and substantial periapical healing.

Keywords: Apical plug, Hydroxyapatite, Open apices, White Portland cement.

How to cite this article: Deshpande SS, Bansode PV. A Novel Approach for Apexification: A 2-year Follow-up Case Report. Int J Prosthodont Restor Dent 2016;6(1)17-20.

Source of support: Nil

Conflict of interest: None

\section{BACKGROUND}

Immature pulpless permanent teeth usually results from trauma and caries. The main challenge in performing rootcanal treatment in teeth with necrotic pulps and wideopen apices is to obtain an optimal apical seal. The wide foramen requires a large volume of filling material that may extrude from the root canal into the periapical tissues creating foreign-body responses and compromising the apical seal. ${ }^{1}$ Several procedures utilizing different materials have been recommended to induce root-end barrier formation. Apexification with calcium hydroxide is the most commonly advocated therapy for immature teeth with nonvital pulp and the healing rate is high (Steiner JC, Dow PR, Cathey GM 1968).

\footnotetext{
${ }^{1}$ Professor, Head, and Postgraduate Guide, ${ }^{2}$ Postgraduate Student

1,2Department of Conservative Dentistry and Endodontics Government Dental College and Hospital, Aurangabad Maharashtra, India

Corresponding Author: Sagar S Deshpande, Postgraduate Student, Department of Conservative Dentistry and Endodontics Government Dental College and Hospital, Aurangabad, Maharashtra India, Phone: +919970756036, e-mail: sagarmdsmumbai@ gmail.com
}

However, calcium hydroxide apexification techniques have a number of disadvantages. For example, the treatment requires compliance from the patient and many appointments over a period of time ranging from 3 to 24 months. $^{2}$ During this period, the root canal is susceptible to reinfection around the provisional restoration, which may promote apical periodontitis and arrest of repair. Other disadvantages in this lengthy treatment include financial concerns and esthetic demands. In addition, it has been reported that the fracture strength of immature teeth may be reduced by long-term calcium hydroxide treatment (Andreasen JO, Farik B, Munksgaard EC 2002). One alternative for calcium hydroxide apexification is a single-step technique using an artificial apical barrier. The one-visit apexification has been described as the nonsurgical compaction of a biocompatible material into the apical end of the root canal, thus, creating an apical stop and enabling immediate filling of the root canal. ${ }^{3}$

Mineral trioxide aggregate (MTA) has been suggested for one-visit apexification. ${ }^{4}$ Mineral trioxide aggregate is widely used in procedures ranging from pulp capping to furcal perforation repair (Torabinejad M, Watson TF, Pitt Ford TR 1993). These applications are possible due to the favorable properties of MTA including biocompatibility (De-Deus et al 2005), good canal sealing ability, and the ability to promote dental pulp and periradicular tissue regeneration (Torabinejad M, Chivian N 1999). It has been reported that MTA, when applied as an apical plug, favored apexification and periapical healing, regardless of the prior use of calcium hydroxide paste. ${ }^{5}$ Other advantages include predictable apical closure and reduced treatment time, number of appointments, and radiographs, particularly in young patients.

Another author reported that MTA and White Portland Cement were almost identical macroscopically, microscopically, and when evaluated by X-ray diffraction analysis. ${ }^{6}$ The first investigation of White Portland Cement for dental use demonstrated that it had similar properties to gray MTA. ${ }^{7}$ The authors also verified that White Portland Cement contained the same principal chemical elements as MTA, except for the radiopacifier bismuth oxide. It has been demonstrated that MTA and White Portland Cement had no cytotoxic effects 
on Chinese hamster ovary cells and reported that these results might be an additional argument to support the use of White Portland Cement in dental practice (Ribeiro D, Marques M, Salvadori D 2006). Histological evaluation of pulpotomies in dogs using MTA and White Portland Cement reported that both were effective as pulp protection materials. ${ }^{8}$ One study showed that the bacterial leakage of Pro-Root MTA and White Portland Cement in furcation repairs were similar up to 50 days. ${ }^{9}$ Due to these favorable results and its low cost, the authors suggested that it was reasonable to consider White Portland Cement as a possible substitute for MTA in endodontics.

A major concern regarding the use of water-based cements is the amount of arsenic present in the material (Islam I, Chng HK, Yap AU 2006). Arsenic is an impurity of limestone that is used in the manufacture of White Portland Cement. The levels of arsenic released were found to be similar for White Portland Cement and MTA, and were below those considered to be dangerous, ${ }^{10}$ demonstrating no contraindication for using these materials in clinical practice.

This case report demonstrates nonsurgical management of large periapical lesion and management of open apex by using hydroxyapatite as apical barrier and White Portland Cement as an apical plug.

\section{CASE DESCRIPTION}

A 21-year-old male reported to the Department of Conservative Dentistry, Government Dental College and Hospital, Aurangabad, 2 years before with complain of pain and discoloration in upper anterior teeth since a year. History of trauma dated many years ago. Root-canal treatment was done in some private clinic 1 year back. Patient gave noncontributory medical history.

Clinical examination revealed that tooth \#21 was discolored and tender. Tooth \#21 had crown fracture at gingival third, with sinus tract near root apex of the same tooth. Radiographic examination indicated improperly obturated tooth \#21 with wide open apex, large periapical radiolucency involving periapical region of both \#21, 22 , thin root dentinal walls, and loss of coronal tooth structure with tooth \#21 (Figure 1). Vitality test was performed by using electrical pulp tester on tooth \#22, which showed a normal response when compared with normal contralateral tooth.

After monitoring all clinical, radiographic findings, diagnosis of pulpless tooth with large periapical lesion with tooth \#21 was made. Treatment plan was advised to patient including retreatment of tooth \#21 with nonsurgical management of periapical lesion followed by apexification by using hydroxyapatite as an internal matrix and White Portland Cement as an apical plug.

The procedure and possible outcomes of apexification with White Portland Cement were explained to the patient and an informed consent was taken. At first visit, rubber dam was applied and access cavity preparation was redefined. Previous gutta-percha filling was removed by using H files (Mani, Inc. Japan) with careful instrumentation to avoid extrusion of gutta-percha through the open apex. A small amount of gutta-percha still remained on the distal wall at the apical third of root canal. The canal was cleaned using hand instruments (K-Files; Mani, Inc., Japan) with minimum instrumentation to avoid further weakening of thin root dentinal walls. Instrumentation was followed by thorough irrigation with $2.5 \%$ sodium hypochlorite with controlled pressure to avoid forceful extrusion of irrigating solution. Final irrigation was performed by saline solution.

The canals were dried with sterile absorbent points and triple antibiotic paste was made by using distilled water and coated on canal walls with the help of spreader. Temporary restoration was given and recalled after 3 weeks.

At recall visit, the patient was asymptomatic. Temporary restoration was removed and canal was checked for any exudate. After confirming dryness of canal and reduced patients symptoms apexification was planned. With the intention to create a periapical barrier for the White Portland Cement, hydroxyapatite was mixed with saline carried with amalgam carrier pushed to the root apex with hand pluggers beyond the canal apex until the periapical space was full. This procedure was adapted from the method described previously by Bargholz (2005). Following the placement of hydroxyapatite, White Portland Cement powder was mixed with sterile water to a soft paste consistency. The White Portland Cement was delivered to the apical portion of the canal (approximately $4 \mathrm{~mm}$ ) using a messing gun and pluggers under an operating microscope, creating an apical plug of $4 \mathrm{~mm}$ thickness (Fig. 2). Series of radiographs were taken to determine that White Portland Cement was placed correctly. Moist cotton dressing was given and the patient was recalled after 24 hours. Gutta-percha obturation of the remaining canal was done.

Coronal portion was seemed to be insufficient to support full-coverage prosthesis, hence post and core placement were planned to get additional retention. After placement of post and core, porcelain fused to metal crown was placed over it. Patient was then recalled at 3, 6, 18, and 24 months' follow-up (Figs 3 and 4). 


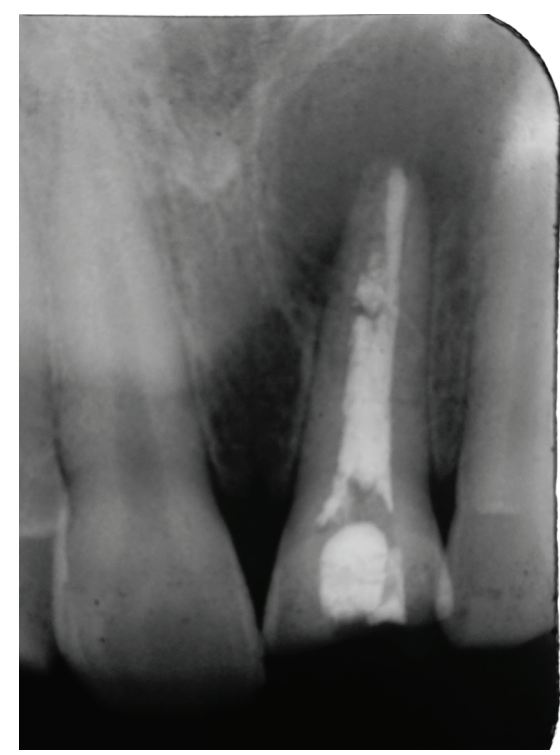

Fig. 1: Improperly obturated root canal with wide open apex, thin root dentinal walls, loss of coronal tooth structure with tooth \# 21, large periapical radiolucency involving periapical region of tooth \# 21, 22

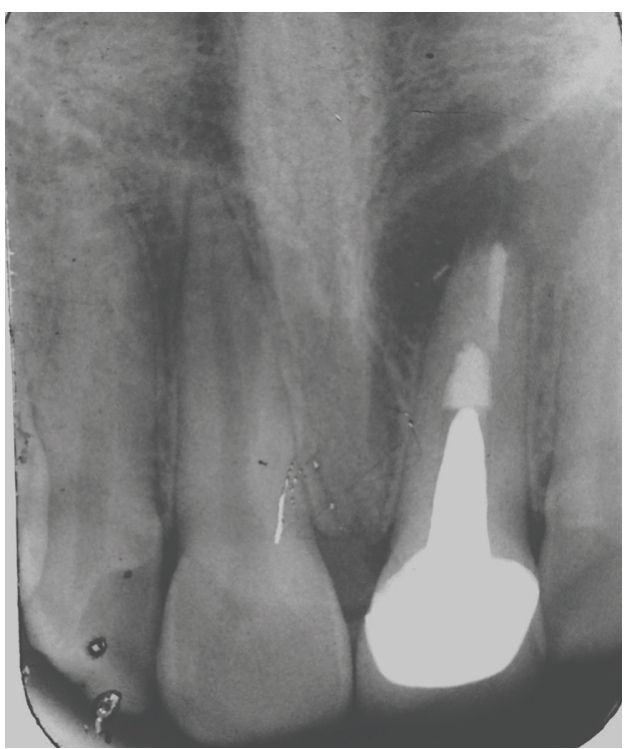

Fig. 3: 18 months follow up radiograph showing resolved periapical lesion around periapical region with tooth \#22 and resolving periapical lesion around periapical lesion with tooth \#21 with post and core and crown prosthesis

\section{CONCLUSION}

Two-year follow-up revealed adequate function, absence of clinical symptoms, and reduced periapical rarefaction. So here we used White Portland Cement as an apical plug and achieved good clinical outcome, which is quite encouraging.

\section{CLINICAL SIGNIFICANCE}

White Portland Cement has been classified into five types with subtypes for the first three. ${ }^{11}$ In most cases, White Portland Cement in dentistry generally refers to type I variety of cement. White Portland Cement has been

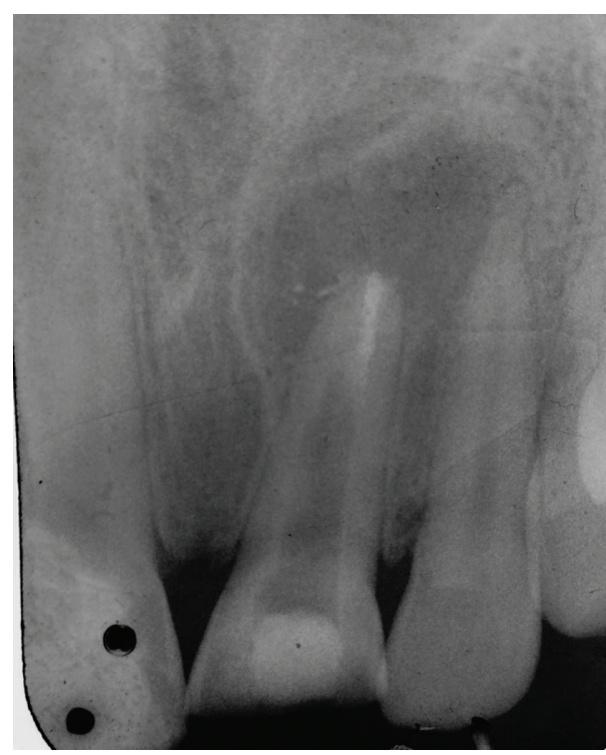

Fig. 2: Radiograph showing tooth \#21 after placement of hydroxyapatite internal matrix and portland cement apical plug Note some gutta-percha still remained on the distal wall at apical third on tooth \#21 and resolving periapical lesion

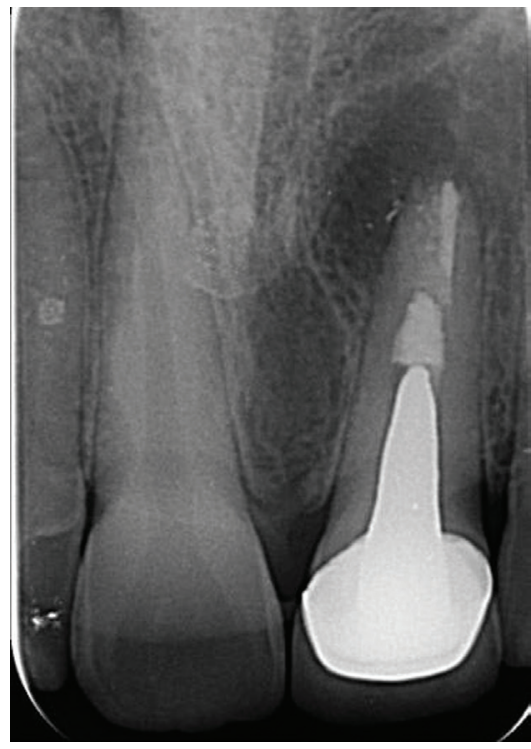

Fig. 4: 24 months follow up radiograph showing almost complete resolved periapical lesion around tooth \#21

proposed as a potential material to create an apical plug in teeth with immature apices.

Previous reports have demonstrated the biocompatibility of White Portland Cement (Holland et al 2001, Abdullah et al 2002) active stimulation of cells through the production of cytokines and a bone-specific protein was noted. The results observed with MTA and White Portland Cement and the mechanism of action of MTA and White Portland Cement are similar (Holland et al 2001).

One author showed that two brands of MTA and White Portland Cement created an elevated cytotoxic effect initially that decreased gradually allowing the 
cell culture to repair (De-Deus et al 2005). Cell reaction patterns were similar for Pro-Root MTA, MTA Angelus, and White Portland Cement at all experimental periods. The authors concluded that the positive results achieved with White Portland Cement were encouraging for its use as an endodontic restorative material with lower cost.

Funteas et al (2003) analyzed samples of MTA and White Portland Cement for 15 different elements using inductively coupled plasma emission spectrometry. Comparative analysis revealed that there was significant similarity, except for the nondetectable quantity of bismuth in White Portland Cement.

To test the sealing ability, an orthograde plug of White Portland Cement was evaluated with fluid filtration technique, which is a more sensitive and reproducible method (De-Deus $G$ et al 2006). The results suggest that White Portland Cement has the potential to be developed as a furcation repair material, even though leakage was noted. One possible reason for the sealing ability of White Portland Cement is its slight expansion upon setting. Mean expansion at 24 hours was noted to be $1.02 \%$ for gray MTA, $0.29 \%$ for White Portland Cement, and 0.08\% for White MTA in water immersion. ${ }^{12}$

From a practical point of view, MTA and White Portland Cement can both be used in moist environments. This is an interesting property during the treatment of teeth with necrotic pulps and periapical lesions because one of the problems found in these cases is the presence of tissue fluid exudate. A practical difference between MTA and White Portland Cement is the lack of radiopacity of the latter. Figure 2 reveals that the radiopacity of White Portland Cement was similar to that of dentin. In the present case, the lack of radiopacity complicated but did not hinder the correct insertion of the material.

As the process of cement manufacture requires $1,500^{\circ} \mathrm{C}$ temperature, owing to the high alkalinity of Portland cement, generally the commercially available samples are found to be sterile. While contaminated samples can be suitably sterilized with no microbial growth seen after dry heat sterilization, gases, or by autoclaving, the physical properties after sterilization need further evaluation. ${ }^{13}$

In this case, White Portland Cement acted as an efficient apical barrier in the wide-open apex of an infected rootcanal system over the internal matrix of hydroxyapatite. Lemon (1992) developed the internal matrix concept in which an intermediate layer of material is placed to form a barrier prior to placement of the repair material. Hydroxyapatite (Lemon 1992), decalcified freeze-dried bone (Hartwell and England 1993), calcium hydroxide (Petersson et al 1985), and sterile bovine collagen have also been advocated as a matrix for perforation repairs. In the current case, hydroxyapatite was chosen as the matrix. This matrix concept was described previously by Bargholz (2005) who reported that it could conform to the root-canal shape. In the presented cases, the hydroxyapatite was shown to be very effective.

\section{ACKNOWLEDGMENT}

I am thankful to following authors for having their names included in the article:

Steiner JC, Dow PR, Cathey GM, Andreasen JO, Farik B, Munksgaard EC, Torabinejad M, Watson TF, Pitt Ford TR, De-Deus, Chivian N, Ribeiro D, Marques M, Salvadori D, Islam I, Chng HK, Yap AU, Bargholz, Holland et al., Abdullah et al., Funteas et al., Petruccelli V, Gurgel Filho E, Coutinho Filho T, Lemon, Hartwell \&; England, Petersson et al.

\section{REFERENCES}

1. Rafter M. Apexification: a review. Dent Traumatol 2005 Feb;21(1):1-8.

2. Frank AL. Therapy for the divergent pulpless tooth by continued apical formation. J Am Dent Assoc 1966 Jan;72(1):87-93.

3. Steinig TH, Regan JD, Gutmann JL. The use and predictable placement of mineral trioxide aggregate in one-visit apexification cases. Aust Endod J 2003 Apr;29(1):34-42.

4. Shabahang S, Torabinejad M. Treatment of teeth with open apices using mineral trioxide aggregate. Pract Periodontics Aesthet Dent 2000 Apr;12(3):315-320; quiz 322.

5. Felippe WT, Felippe MCS, Rocha MJC. The effect of mineral trioxide aggregate on the apexification and periapical healing of teeth with incomplete root formation. Int Endod J 2006 Jan;39(1):2-9.

6. Wucherpfennig AL, Green DB. Mineral trioxide vs. Portland cement: two biocompatible filling materials. J Endod 1999;25:308.

7. Camilleri J, Pitt Ford TR. Mineral trioxide aggregate: a review of the constituents and biological properties of the material. Int Endod J 2006 Oct;39(10):747-754.

8. Menezes R, Bramante CM, Letra A, Carvalho VG, Garcia RB. Histologic evaluation of pulpotomies in dog using two types of mineral trioxide aggregate and regular and white Portland cements as wound dressings. Oral Surg Oral Med Oral Pathol Oral Radiol Endod 2004 Sep;98(3):376-379.

9. De-Deus G, Petruccelli V, Gurgel-Filho E, Coutinho-Filho T. MTA versus Portland cement as repair material for furcal perforations: a laboratory study using a polymicrobial leakage model. Int Endod J 2006 Apr;39(4):293-298.

10. Duarte MA, De Oliveira Demarchi AC, Yamashita JC, Kuga MC, De Campos Fraga S. Arsenic release provided by MTA and Portland cement. Oral Surg Oral Med Oral Pathol Oral Radiol Endod 2005 May;99(5):648-650.

11. Islam I, Chng HK, Yap AU. Comparison of the physical and mechanical properties of MTA and Portland cement. J Endod 2006 Mar;32(3):193-197.

12. Storm B, Eichmiller FC, Tordik PA, Goodell GG. Setting expansion of gray and white mineral trioxide aggregate and Portland cement. J Endod 2008 Jan;34(1):80-82.

13. Abdullah D, Pitt Ford T, Papaioannou S, Nicholson J, McDonald F. An evaluation of accelerated Portland cement as a restorative material. Biomaterials 2002 Oct;23(19): 4001-4010. 